\title{
A global assessment of deep-sea basalt sites for carbon sequestration
}

Dave Goldberg and Angela Slagle*

Lamont-Doherty Earth Observatory, 61 Route 9W, Palisades, NY 10964 USA

*contact: aslagle@Ideo.columbia.edu

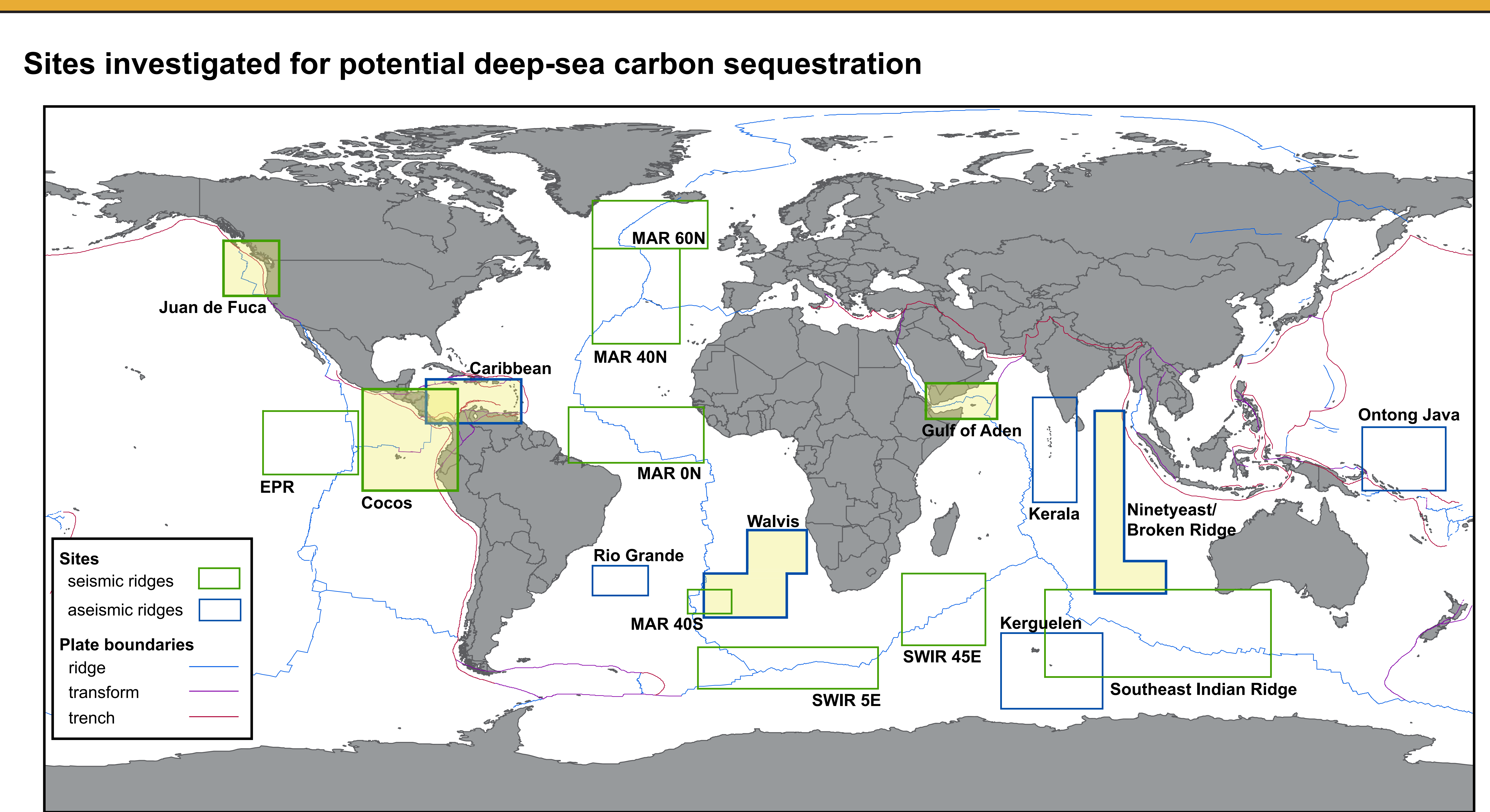

Global sites considered in our assessment for deep-sea basalt $\mathrm{CO}_{2}$ sequestration. Eleven seismic ridge sites (green boxes) and seven aseismic ridge sites
(blue boxes) were identified with sediment thickness $\geq 200 \mathrm{~m}$ for this study. The sites highhighted in yellow are detailed below.

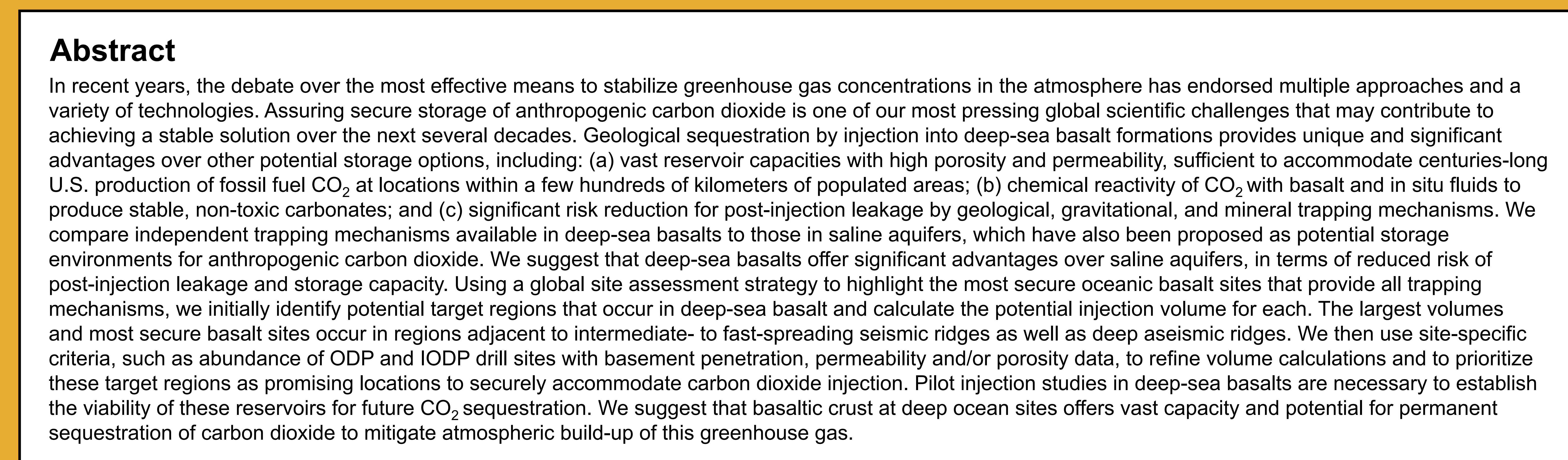

Benefits of Deep-Sea Geological Sequestration in Basalt

- High porosity and storage capacity

- High permeability and injection potential

- Safe and secure long-term $\mathrm{CO}_{2}$ sequestration: Hierarchy of multiple trapping mechanisms

1. Physical Trapping

. Gravitational Trapping
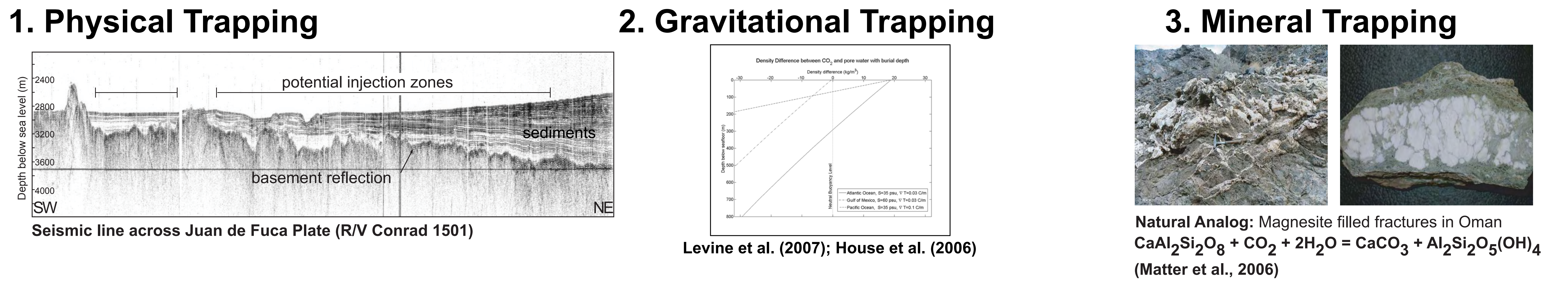

Site Assessment Strategy - Identify deep-sea basalt sites that provide all trapping mechanisms

1. $\geq 200$ meters of sediment cover provides physical trapping (from Divins, 2007)

2. $\geq 2700$ meters of water depth provides gravitational trapping (from the Marine Geoscience Data System, http://www.marine-geo.org; Smith \& Sandwell, 1997).

3. Oceanic basalt provides high permeability layers (e.g. Spinelli and Fisher, 2002) and mineral trapping potential (Goldberg, 1999).
Seismic Ridge Sites

Location maps of potential seismic ridge sites. For each site, the red hatched area represents water
depths $\geq 2700 \mathrm{~m}$ and sediment thickness $\geq 200 \mathrm{~m}$, excluding $20 \mathrm{Km}$ distance from seamounts and crustal atteration (Jarrard et al., 2003). DSDP, ODP, and IODP drillitite locations are indicated by
black circles
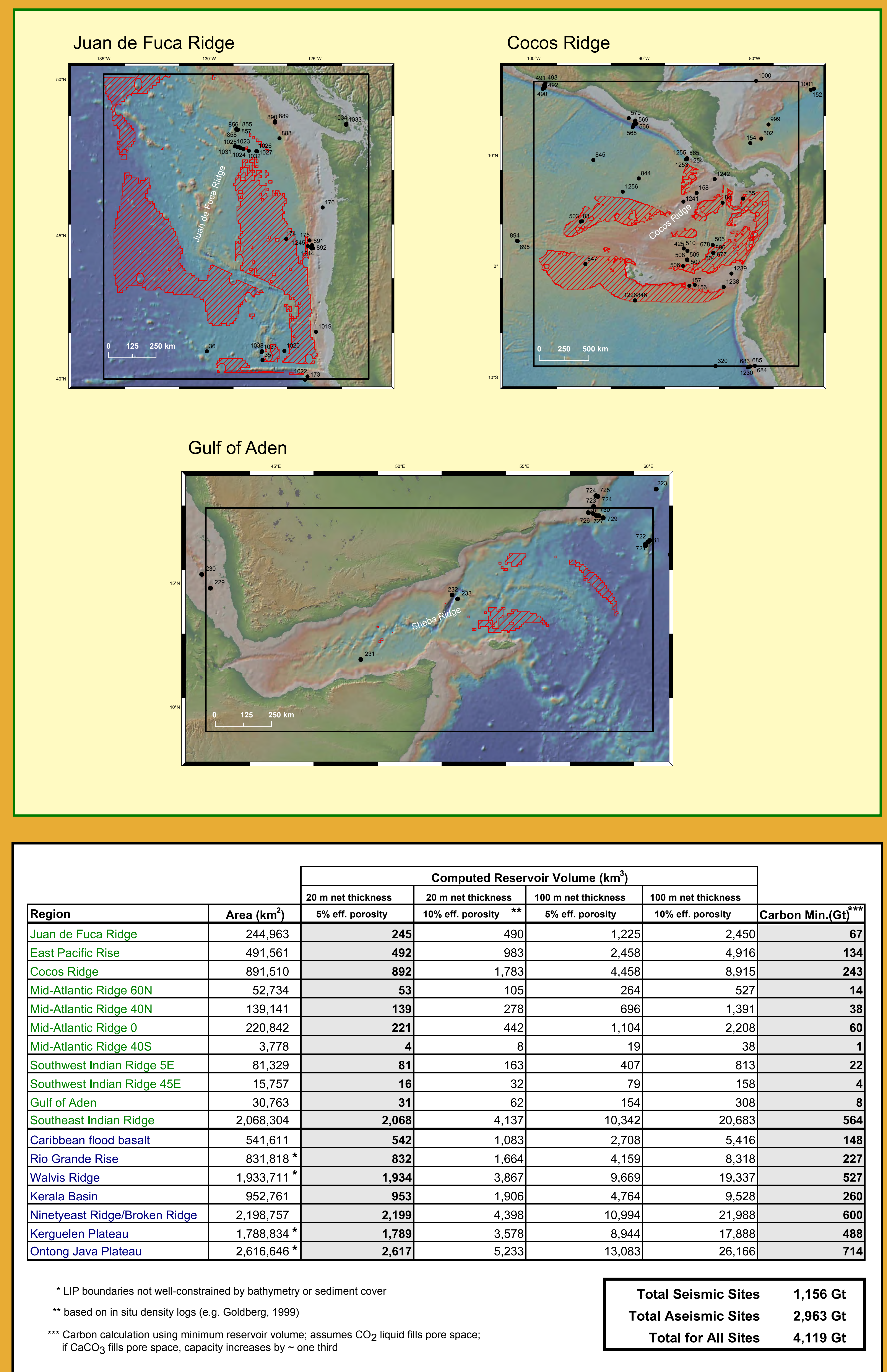

\section{References Cited}

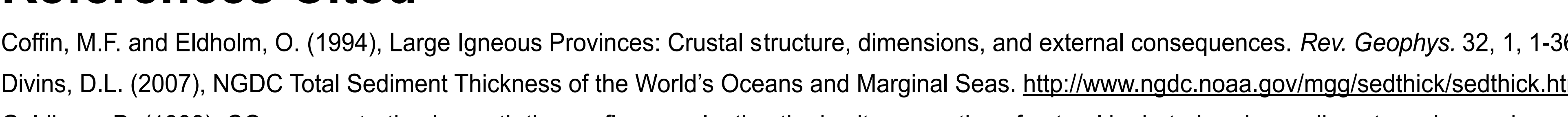

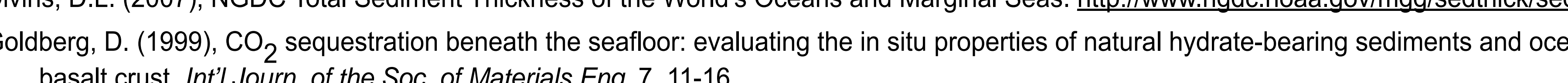

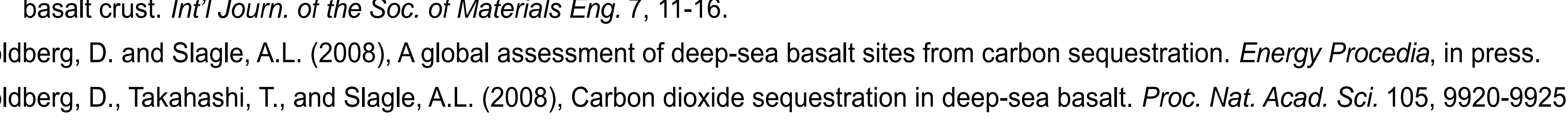

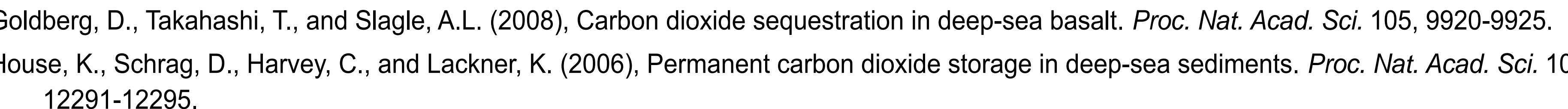

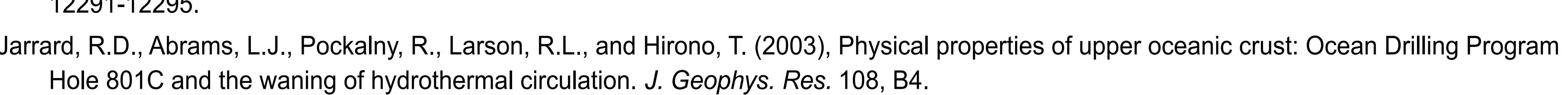

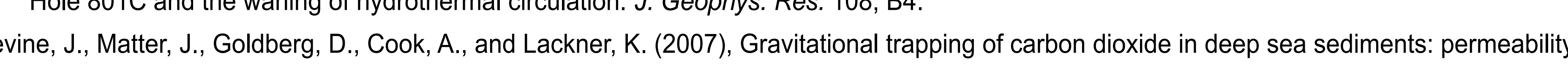

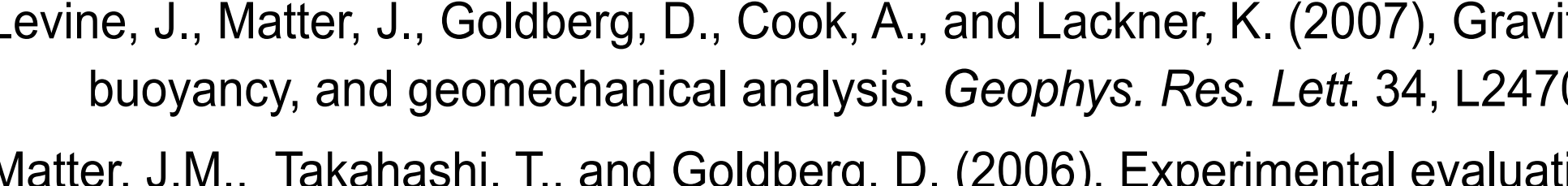

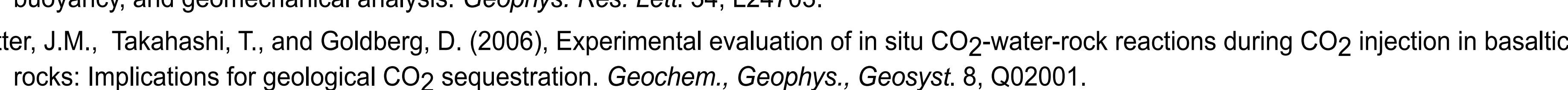

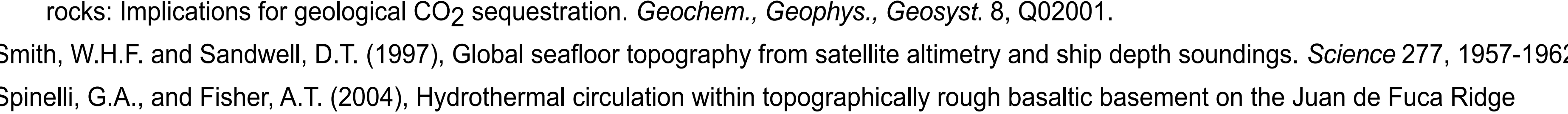

Large Igneous Provinces (Aseismic Ridge Sites)

Location maps of potential aseismic ridge sites (large igneous provinces, in Coffin \& Eldholm, 1994).
For each site, the red hatched area indicates water depths $\geq 2700 \mathrm{~m}$ and sediment thickness

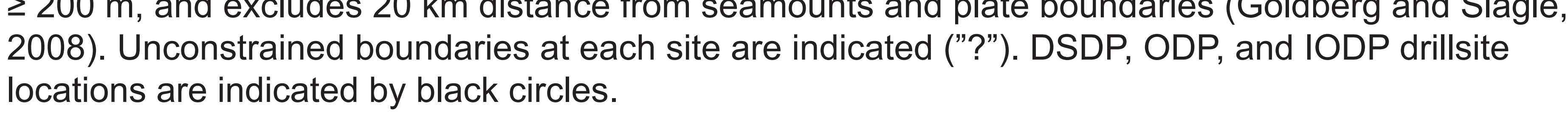
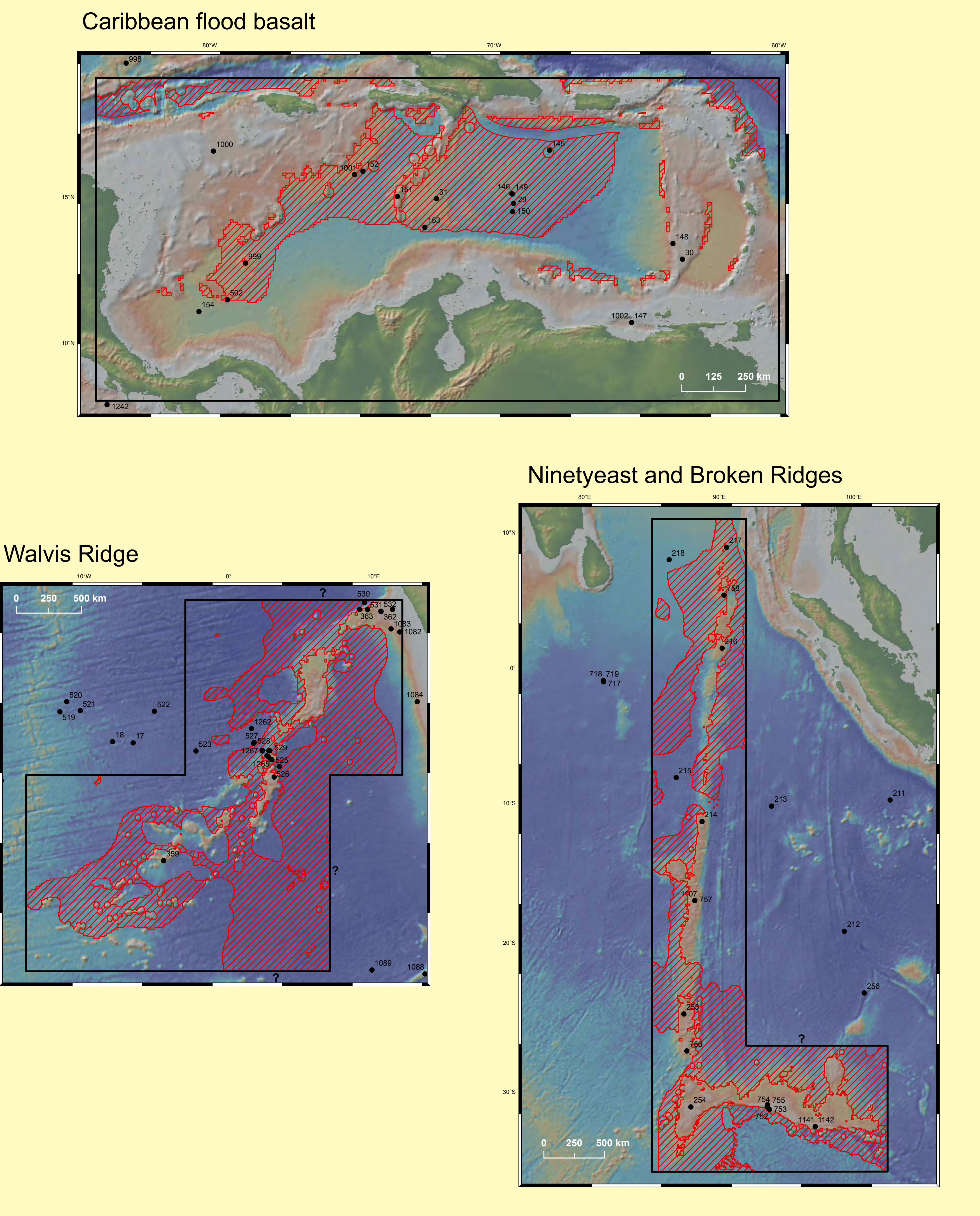

Implications

- At current U.S. annual emission rates of $1.7 \mathrm{Gt}$ Carbon, even individual oceanic basalt ridges have sufficient capacity for tens to hundreds of years of safe and secure sequestration of anthropogenic $\mathrm{CO}_{2}$.

- The worldwide total volume potential is $4.1 \mathrm{Tt}-\mathrm{C}$, assuming the minimum reservoir thickness estimates (see Table). These estimates may be as much as ten times greater than the minimum calculation, for higher porosity and greater reservoir thicknesses. - Large volumes exist at seismic ridges in reasonable proximity to $\mathrm{CO}_{2}$ sources along continental margins, such as the Cocos Ridge, the Juan de Fuca Ridge, and the Sheba Ridge in the Gulf of Aden.

- Aseismic ridge sites may provide three times greater capacity than seismic ridge sites. However, pore volume estimates and

area assessments are significantly less well-constrained.

- Further investigations are needed to measure in situ properties at specific sites. A pilot injection study in deep-sea basalt would establish the viability of these reservoirs for $\mathrm{CO}_{2}$ sequestration. 